\title{
Valuation of Bond Options Under the CIR Model: Some Computational Remarks
}

\author{
Manuela Larguinho, José Carlos Dias, and Carlos A. Braumann
}

\begin{abstract}
Pricing bond options under the Cox, Ingersoll and Ross (CIR) model of the term structure of interest rates requires the computation of the noncentral chisquare distribution function. In this article, we compare the performance in terms of accuracy and computational time of alternative methods for computing such probability distributions against an externally tested benchmark. All methods are generally accurate over a wide range of parameters that are frequently needed for pricing bond options, though they all present relevant differences in terms of running times. The iterative procedure of Benton and Krishnamoorthy (Comput. Stat. Data Anal. 43:249-267, 2003) is the most efficient in terms of accuracy and computational burden for determining bond option prices under the CIR assumption.
\end{abstract}

M. Larguinho $(\square)$

Department of Mathematics, ISCAC, Quinta Agrícola, Bencanta, 3040-316 Coimbra, Portugal e-mail: mlarguinho@iscac.pt

J.C. Dias

BRU-UNIDE and ISCTE-IUL Business School, Av. Prof. Aníbal Bettencourt, 1600-189 Lisboa, Portugal

e-mail: jose.carlos.dias@iscte.pt

C.A. Braumann

Department of Mathematics, Centro de Investigação em Matemática e Aplicações, Universidade de Évora, Rua Romão Ramalho 59, 7000-671 Évora, Portugal

e-mail: braumann@uevora.pt

A. Pacheco et al. (eds.), New Advances in Statistical Modeling and Applications, Studies in Theoretical and Applied Statistics, DOI 10.1007/978-3-319-05323-3_12, (C) Springer International Publishing Switzerland 2014 